\title{
Publisher Correction: Intensity-dependent modulation of optically active signals in a chiral metamaterial
}

Sean P. Rodrigues, Shoufeng Lan, Lei Kang, Yonghao Cui, Patrick W. Panuski, Shengxiang Wang, Augustine M. Urbas \& Wenshan Cai

Nature Communications 8:14602 doi: 10.1038/ncomms14602 (2017); Published 27 Feb 2017, Updated 25 Jun 2018

The original HTML version of this Article had an incorrect article number of ' 0 '; it should have been ' 14602 '. This has now been corrected in the HTML version of the Article. The PDF version was correct from the time of publication.

Open Access This article is licensed under a Creative Commons Attribution 4.0 International License, which permits use, sharing, adaptation, distribution and reproduction in any medium or format, as long as you give appropriate credit to the original author(s) and the source, provide a link to the Creative Commons license, and indicate if changes were made. The images or other third party material in this article are included in the article's Creative Commons license, unless indicated otherwise in

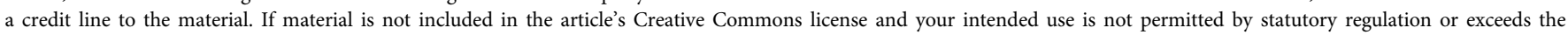
permitted use, you will need to obtain permission directly from the copyright holder. To view a copy of this license, visit http://creativecommons.org/licenses/by/4.0/

(C) The Author(s) 2018 